\title{
BIORREATOR À MEMBRANA-NOVA: TECNOLOGIA PARA TRATAMENTO DE EFLUENTES
}

\section{Joicy Alves Batista}

joicyalves00@hotmail.com Centro Universitário de Goiatuba

- UniCerrado, Goiatuba, Goiás,

Brasil.

\section{Luana Rodrigues Costa}

Costalu005@outlook.com Centro Universitário de Goiatuba

- UniCerrado, Goiatuba, Goiás,

Brasil.

Mylena Luiza de Oliveira mylenaluizaoliveira5@gmail.com Centro Universitário de Goiatuba - UniCerrado, Goiatuba, Goiás, Brasil.

\section{RESUMO}

A maioria das estações de tratamento de esgoto tem seguimentos de processos clássicos, normalmente coagulações-floculações contínuas de tratamentos biológicos. Nota-se que nas grandes metrópoles os problemas de tratamento de esgoto vêm se estendendo, e parte desses efluentes, tanto domésticos quanto industriais, normalmente são lançados ao meio ambiente, acarretando problemas e riscos à saúde da população; portanto, são necessários novos métodos de tratamento para evitar danos e contaminações ao meio ambiente. Além disso, o crescimento dos meios urbanos tem deixado poucas alternativas de áreas disponíveis para a implantação de estações de tratamento de esgoto (ETE), uma vez que estas demandam espaço significativo para a sua instalação. Como alternativas às ETE convencionais surgiu uma nova tecnologia, a partir de um conceito simples de filtração de biomassa: os biorreatores à membrana (MBR). Este artigo visa demonstrar como são realizados os procedimentos de tratamento de efluentes por meio da tecnologia MBR, com a qual temos a possibilidade de trabalhar com elevadas taxas de aplicação, com a viabilidade de um efluente melhorado e com viáveis opções de reuso da água.

Palavras-chave: tecnologia no sistema de tratamento de efluentes, biorreatores a membranas, funcionamento de sistemas de tratamento de efluentes. 


\section{INTRODUÇÃO}

Um sistema devidamente adequado de tratamento de efluente doméstico é indispensável para a proteção das condições de saúde, pois proporciona o controle e a redução do número de infecções e doenças geradas pela água contaminada. A coleta de esgoto melhora a qualidade ambiental e de vida das populações urbanas. No entanto, não exclui os efeitos das emissões do efluente em meios d'água. Por esta razão, o seu tratamento é indispensável para a preservação da qualidade da água de corpos receptores, tal como do ambiente e da saúde da população. O tratamento de esgoto é considerado, pelo Instituto Brasileiro de Geografia e Estatística (IBGE, 2002), um bom precursor de desdobramento humano, já que mostra, principalmente, o nível de qualidade de vida da população domiciliada em um determinado local.

Segundo dados do IBGE (2002), a proporção do esgoto tratado em comparação ao total coletado no Brasil em 1989 era de $19,9 \%$, sendo que naquele ano foram coletados $10.667 .823 \mathrm{~m}^{3}$ por dia. Onze anos depois (2000), o volume total coletado por dia foi de $14.570 .079 \mathrm{~m}^{3}$, e apenas $35,3 \%$ destes foram tratados, ou seja, mais de $60 \%$ ficaram sem o devido tratamento.

Na década de 1960 os EUA já usavam a osmose reversa para dessalinização das águas, mas foi a partir da década de 1990 que a utilização dos recursos de filtração por membranas passou a ser estudado no saneamento. No Brasil, essa estratégia tem sido objeto de estudo de diversas universidades, como a Universidade de São Paulo (USP), Universidade Federal do Rio de Janeiro (UFRJ), Universidade Federal do Rio Grande do Sul (UFRGS), Universidade Estadual de Maringá (UEM) e Universidade Federal de Santa Catarina (UFSC).

Estes estudos, que têm sido desenvolvidos em parceria com os fabricantes de membranas, têm colaborado para que o processo de filtração por membrana diminua aceleradamente, o que poderá contribuir para a sua utilização futura em diversos países.

Entre os processos relacionados à filtração, destacam-se os biorreatores à membrana (Membrane Bio Reactor - MBR), cujo método de utilização tem apresentado um potencial de grande valia para o saneamento, pela ligação do tratamento biológico com a separação pela membrana.

A principal função do biorreator é a de degradar a matéria orgânica e mineral, ao mesmo tempo que a membrana realiza a separação das fases líquidas e sólidas. Esta alternativa apresenta alta eficácia na eliminação de poluentes, gerando baixo consumo de energia necessária para a área reduzida de instalação por trabalhar com altas concentrações de biomassas (Maestri, 2007).
Nas grandes metrópoles, cujo crescimento deixou poucas áreas para implantação estações de tratamento de esgoto (ETE), os MBR funcionam como alternativa viável para o tratamento biológico de efluentes combinado à filtração por membranas.

Embora as tecnologias tipicamente utilizadas para o tratamento de esgotos (processos físico-químicos, sistemas de lodos ativados, lagoas de estabilização, filtros biológicos etc.) sejam aplicadas com sucesso no tratamento de efluentes, elas podem ser substituídas ou combinadas a novas tecnologias que proporcionam águas residuárias, vulgarmente denominadas esgotos, com qualidade de reuso, caso dos MBR que se destacam enquanto uma variante dos processos microbiológicos, diferenciando-se pela substituição do decantador secundário por uma unidade de membrana de micro ou ultra filtração.

Pelo exposto, o objetivo geral deste estudo de revisão é analisar como são realizados os procedimentos de tratamento de efluentes através dos MBR, os quais viabilizam um efluente melhorado e com opções viáveis de reuso. Como objetivos específicos foram delineados: avaliar a competência dos MBR na retirada de contaminantes de esgotos sanitários; analisar o desenvolvimento da biomassa no biorreator; e qualificar o permeado para o seu aproveitamento.

\section{REVISÃO BIBLIOGRÁFICA}

Na retaguarda, à Revolução Industrial iniciada no século XVII sucedeu um modelo social que incorreu, por exemplo, na amplificação e distribuição de bens de consumo em volumes cada vez maiores e com ritmos cada vez mais acelerados. A análise dos recursos naturais foi seguida com o desenvolvimento industrial, que ao longo do tempo provocou um grande desequilíbrio ambiental, visto a somatória de diversos fatores, como a extração descontrolada de matérias-primas naturais e produção de rejeitos (sólidos, líquidos e gasosos) compostos por diversas substâncias utilizadas. Outro fator associado à Revolução Industrial é a urbanização que desencadeou uma alta demanda por bens de consumo (Goulart e Callisto, 2003).

Dada as apreensões crescentes sobre a economia gerada pela água e sobre as limitações da legislação, a reutilização da água tem sido tema de interesse no contexto mundial. Buscam-se alternativas para a integração de diferentes atividades de modo que a água de rejeito de um determinado processo seja utilizada de modo direto em outro processo que precise de água de menor qualidade, contribuindo, assim, para a economia de água e preservação de fontes de abastecimento (poços e águas de superfícies). Outra possibilidade é a reutilização da água em um ciclo fechado, no qual todo o efluente gerado deve ser tratado, empregando um processo adequado, e reutilizado. 
Sobre isso, questiona-se: Os efluentes vêm sendo tratados? De que maneira?

\subsection{Tratamento de efluentes}

O tratamento de efluentes industriais são regidos pela NBR 9800/1987, aos quais são incorporados os rejeitos líquidos proveniente das atividades industriais, águas de refrigeração, de vias pluviais poluídas, e esgotos domésticos (ABNT, 1987). Os efluentes apresentam inúmeros efeitos toxicológicos no meio ambiente e na saúde pública. Tal circunstância deve-se à complexidade física, química e biológica de qualquer rejeito levado diretamente pelos processos produtivos. Os principais parâmetros a serem apontados no descarte de efluentes são a turbidez, cor, concentração de oxigênio dissolvido, concentração de sólidos totais dissolvidos, $\mathrm{pH}$, dureza, temperatura, concentração de nitrogênio e fósforo totais, microrganismos patogênicos, demanda química de oxigênio (DQO), demanda biológica de oxigênio (DBO) e alcalinidade (Dezotti, 2008). Os parâmetros indicados neste controle não implicam na qualidade e no descarte apropriado dos efluentes em um corpo dado como receptor; neste sentido, cada rejeito possui características relacionadas à sua origem, como compostos específicos que muitas vezes, mesmo em baixa concentração, desencadeiam desequilíbrio ambiental.

Em geral quando se diz tratamento de efluentes, são caracterizados alguns níveis que podem auxiliar na compreensão de sua eficiência. Tais níveis que podem ser definidos como níveis preliminares, primário, secundário, terciário e níveis avançados que se resultam na combinação de diversas operações unitárias.

Os efluentes são definidos como todo o resíduo e material indesejado retirado em um processo industrial ou doméstico. As impurezas podem ser matéria orgânica ou inorgânica, rompida ou em suspensão, como microrganismos, metais pesados, óleos e graxas. Consequentemente, o tratamento adequado para um determinado efluente depende da quantidade e tipo de matéria que o compõe. Além disso, existem características indesejadas como acidez, alcalinidade, turbidez, toxicidade, cor e odor, que resume o tipo de resíduo ali contido e são fatores considerados no tratamento. Além disso, definem-se os efluentes como sendo industriais ou domésticos.

\subsubsection{Efluentes industriais}

Esse grupo engloba os rejeitos produzidos durante o processo industrial e que não são mais aproveitados pela empresa. Como as classes de indústrias são muitas, os rejeitos industriais também são diversificados (exemplo: rejeitos da mineração; rejeitos orgânicos da indústria alimentícia). Vale ressaltar que existem legislações federais que determinam proibições e parâmetros no que tange à minimização de prejuízos ao meio ambiente, como a Lei da Política Nacional do Meio Ambiente.

\subsubsection{Efluentes domésticos}

Mesmo tendo menos potencial poluente, os materiais produzidos em nossas casas também geram sérios danos ao meio ambiente. $\mathrm{O}$ alto nível de material orgânico pede um destino adequado, e os eventuais produtos químicos aumentam o impacto ambiental. São exemplos de efluentes domésticos: esgoto de prédios e de edifícios comerciais; caixas de gordura de casas, restaurantes e lanchonetes; e fossas sépticas, muito naturais em áreas rurais.

Segundo Mello (2018), O processo de tratamento de efluentes engloba diversas etapas que podem gerar processos físicos, químicos ou biológicos.

\subsection{Tratamento preliminar}

No tratamento preliminar, mediante processos físicos, ocorre uma redução de sólidos grosseiros, isto é, de materiais com um diâmetro acima de $10 \mathrm{~mm}$. Também é utilizado um peneiramento para fazer a remoção de material grosseiro de diâmetros menores (caixa de retenção de gordura). No entanto, dependendo do pH e do volume do efluente, as etapas de neutralização e homogeneização poderão ser adicionadas.

\subsection{Tratamento primário}

Para o tratamento primário, a remoção dos sólidos em suspensão ocorre através de procedimentos de coagulação, floculação, sedimentação e flotação. Durante a coagulação e a floculação ocorre o mecanismo de remoção de partículas de sujeiras, com dosagem de sulfato de alumínio, fazendo com que os flocos se movimentem ganhando peso, volume e consistência. A sedimentação constitui-se na separação sólido-líquido por diferença de densidade, fazendo com que o sólido se acumule no fundo, e a sua velocidade seja adequada ao tamanho das partículas. Já a flotação se baseia na adição de bolhas de ar. As partículas se aglutinam às bolhas, formando um conjunto de densidade menor que o fluido, gerando uma espuma na superfície que é removida adiante.

\subsection{Tratamento secundário}

O propósito gerado através do tratamento secundário consiste na aplicação de métodos biológicos aeróbios e 
anaeróbios. A ideia é aproveitar o metabolismo de microrganismos para a retirada da matéria orgânica biodegradável presente, que atua como substrato para estes microrganismos. Como resultado, há crescimento da biomassa e este lodo formado pode ser sedimentado e circulado no processo de aumento de eficiência de remoção de matéria-orgânica.

\subsection{Tratamento terciário}

O tratamento de efluente de nível terciário é pouco utilizado nos processos industriais, entretanto, este tratamento torna-se indispensável para que a qualidade necessária para reutilização de insumos no processo industrial seja atingida. Sua etapa final é a redução de toda a carga de sólidos em suspensão, micropoluentes, microrganismos e carga orgânica que persistiram às fases anteriores. Algumas das técnicas utilizadas são lagos de maturação para destruição de microrganismos, principalmente patogênicos, filtração e processos com membranas para retenção de sólidos em suspensão, adsorção de micropoluentes em carvão ativado, troca iônica e oxidação química. Após a realização desses procedimentos, o efluente tem qualidade suficiente para ser descartado de forma segura.

As atuais tecnologias para o tratamento de efluentes são bastante diversificadas. Aqui serão apresentadas algumas opções, com destaque para novas tecnologias; em específico, será analisado com maior precisão o método MBR.

É essencial saber que o tratamento de efluentes geralmente faz com que os resíduos humanos e industriais sejam eliminados sem oferecer risco à saúde da população ou gerar consequências ao meio ambiente, tornando-os aptos ao reuso, mitigando, assim, os impactos que podem ser gerados em razão da falta de água.

É notável que as indústrias vem desempenhando um papel de grande relevância no tratamento de água e efluentes, fazendo com que novas tecnologias se tornem eficientes para a purificação de resíduos antes de serem descartados, conforme as exigências dos órgãos ambientais.

É de suma importância ressaltar a aplicabilidade das etapas do tratamento de água e efluentes. Estes são planejados para atingir melhorias na qualidade dos efluentes e águas e reduzir: sólidos em suspensão; produtos orgânicos biodegradáveis; bactérias e outros organismos patogênicos; e nutrientes (incluindo nitrato e fosfato).

\subsection{Tecnologias de tratamento de água e efluentes}

- Processos físicos mais comuns

Em efluentes com substâncias ou coloides insolúveis em água os processos físicos utilizados são a decantação, filtração ou separação centrífuga. Além do mais, são empregadas grades, filtros ou membranas de filtração.

\section{- Membranas de filtração}

Este termo é utilizado para designar diferentes processos físicos de separação que têm em comum o uso de membranas, porém de diferentes tipos. Este tratamento de água e efluentes tem por objetivo separar as substâncias consideradas solúveis e insolúveis das águas residuais, atraindo o líquido a passar por uma membrana semipermeável. Alguns dos pontos positivos deste processo são: não exige adição de produtos químicos; baixo emprego de energia; e fácil aplicação e condução dos processos.

\section{- Flotação}

Dependendo da composição das águas residuais, pode ser necessário o emprego de um processo físico chamado flotação, o qual utiliza forças de adesão para que partículas mais finas sejam separadas por aderirem a pequenas bolhas de ar.

- Processos químicos de tratamento

É um método de adição de produtos químicos para acelerar a desinfecção dos efluentes. Estes induzem reações químicas, geralmente associadas a processos biológicos e físicos para maior eficiência. Os processos químicos mais comuns são a coagulação química; a precipitação química; a oxidação; a permuta iônica; e a neutralização e estabilização.

\section{- Tratamento biológico}

Métodos de tratamento biológico utilizados para remover matéria orgânica dissolvida e suspensa em águas residuais. As condições ambientais são aprimoradas para estimular o crescimento de microrganismos que utilizam compostos orgânicos como substratos. Estes processos de tratamento de água e efluentes também removem outros componentes de águas residuais, como: sólidos em suspensão; nitrogênio; fósforo; metais pesados; e xenobióticos.

\subsection{Tratamento por biorreatores de membrana}

Os MBR são o resultado da combinação do processo de tratamento biológico de efluentes e da separação por mem- 
brana. Normalmente este processo tem ligação similar ao tratamento convencional de efluentes, a não ser pelo sistema de separação do lodo ativado e da água tratada. A principal função das membranas é reter a biomassa, substituindo os decantadores das estações de tratamento biológico convencionais. As membranas são capazes de reter o líquido total localizado nas biomassas, e reduzem significativamente a área ocupada pelas instalações de tratamento, garantindo a produção de efluentes mais bem tratados e de melhor qualidade (Holbrook et al., 2005).

Este procedimento passou a ser adotado no final dos anos 1960, quando as membranas comerciais de micro e ultrafiltração foram liberadas no mercado. Smith et al. (1969) lançaram o projeto original, combinando o uso dos reatores de lodo ativado com as membranas, operando em fluxo tangencial. Na ocasião, este projeto não atraiu tanto interesse por conta dos gastos que as membranas ocasionaram, do baixo valor econômico do produto e do seu elevado potencial de perda de desempenho por meio das suas incrustações.

Mais tarde, Yamamoto et al. (1989) redescobriram o método com a ideia de utilizar membranas submersas localizadas dentro dos reatores. Estas necessitavam de um espaço próprio para as suas instalações, de altas pressões e velocidades tangenciais. Outro passo importante do processo, segundo os autores, foi a aceitação de fluxos modestos e a ideia de utilização de borbulhamento para ter o controle das incrustações.

Outros aprimoramentos foram sendo introduzidos a partir dos anos 1990, incluindo a redução considerável dos custos para a produção das membranas, o que permitiu o uso deste processo nas indústrias.

São dois os tipos de MBR disponíveis para o tratamento de efluentes domésticos ou industriais: com módulos externos ao tanque de aeração (Figura 1) e com módulos submersos ao tanque de aeração (Figura 2). Estes reatores têm configurações tipo casco-tubo, placas, quadro, ou fibra oca.

Nos módulos externos, os conteúdos contidos nos reatores são bombeados para os módulos, normalmente tubulares. Este processo opera fluxo cruzado, ou seja, a solução escoa paralelamente à superfície da membrana, enquanto o permeado é transportado transversalmente à mesma.

Apesar de MBR com modulo externo serem simples e de fácil operação, apresentam consumo energético elevado para permitir a diferença de pressão necessária à permeação e par fornecer velocidade à suspensão. O elevado cisalhamento produzido na circulação da solução suspensa pode provocar a liberação de macromoléculas do interior das células, aumentando a concentração de compostos que podem ser absorvidos nos poros das membranas, diminuindo assim o seu fluxo.

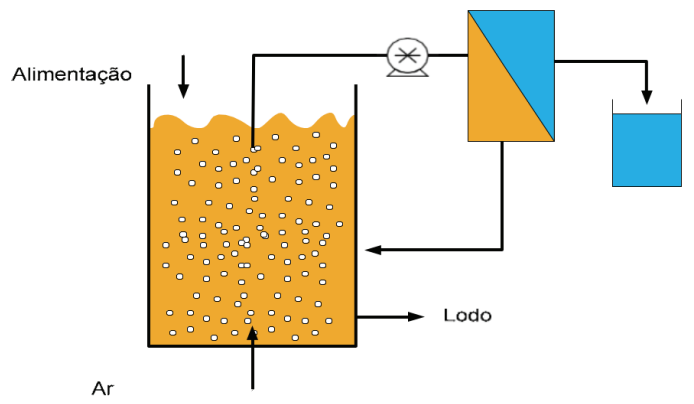

Figura 1. Módulo de membranas externo ao tanque de aeração Fonte: Maestri, 2007.

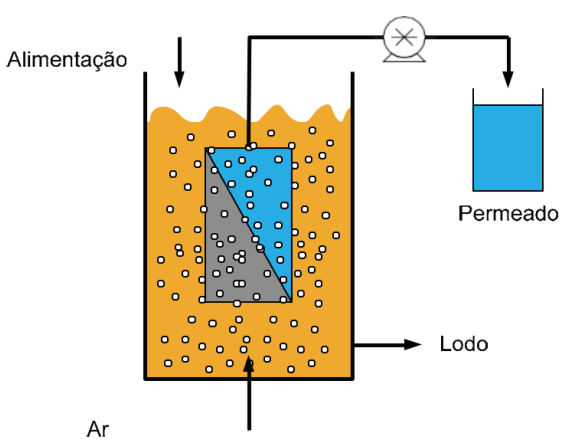

Figura 2. Módulo de membranas submerso no tanque de aeração Fonte: Maestri, 2007.

No reator submerso, o modulo ou feixe de membrana é imerso no tanque aerado, e o seu conteúdo está em contato com a superfície externa das membranas. O permeado é alcançado por meio de sucção do conteúdo do reator que atravessa as paredes da membrana. A diferença de pressão pode gerar uma separação provocada pela coluna do líquido no interior do reator, ou aplicando-se vácuo no lado do permeado.

As membranas submersas utilizam um tipo de fibra oca, ou placa plana. Enquanto as membranas planas são instaladas verticalmente, as ocas podem ser instaladas tanto verticalmente, quanto horizontalmente. Neste tipo de membrana, a aeração tem como funções: fazer a manutenção da limpeza na sua superfície, fornecer oxigênio para comunidade microbiana, e manter a suspensão da biomassa no interior do reator.

A força de cisalhamento gerada sobre a suspensão é menor do que aquela produzida para os sistemas de módulo externo; como resultado, tem-se flocos de lodo ativado com características melhores. A turbulência presente no tanque aerado e o efeito das bolhas tornam-se suficientes para a produção de condições e operações satisfatórias para a 
manter o fluxo praticamente constante, aumentando a pressão transmembrana (PTM) baixa.

Os módulos de membranas submersas são normalmente denominados feixes de membranas, pois são empregados arranjos de fibras sem uma determinada carcaça envoltória. Para utilização industrial, as fibras são preparadas de modo que ambas as extremidades de cada uma delas fiquem presas e fechadas em uma resina sólida, evitando a contaminação do permeado extraído através do interior das fibras.

A principal vantagem do módulo submerso é o baixo consumo energético. É evidente que a energia necessária para a produção de vácuo para os biorreatores é, frequentemente, menor que a energia aplicada para os biorreatores de módulo externo, que utilizam bombas do tipo centrífugas ou de deslocamento positivo. Porém, os fluxos permeados através dos módulos submersos são menores quando comparados aos obtidos com os de módulos externos.

Entre as dificuldades para a utilização de MBR destacam-se a polarização de concentração e as incrustações. A relação entre a membrana e o conteúdo do reator ocorre em todos os processos de separação com membranas e reduzem o fluxo do permeado.

Geralmente, a técnica de operação aplicada para a manutenção do fluxo permeado estável consiste na permeação, alcançada por sucção, alternada com retrolavagem, na qual uma porção do permeado é bombeada no sentido contrário ao da permeação. Faz-se necessário evidenciar que, ao invés do permeado, alguns autores utilizam o ar para realizar a operação de retrolavagem.

\subsubsection{Aspectos importantes em MBR}

Mesmo com as tecnologias mais simples para o tratamento de esgoto, como as lagoas, até às mais avançadas, como as MBR, há diversos fatores externos que interferem no desempenho dos métodos de tratamento, são eles: oscilação de clima, variação e temperatura na caracteristica do afluente.

Outros parâmetros adequados à operação, possíveis de se controlar são a concentração de oxigênio, o pH e a concentração da biomassa, considerados comuns nas etapas de tratamento de esgotos com biomassa em suspensão.

Outros fatores que podem influenciar o desempenho das MBR são:

- Aeração, que fornece oxigênio para os microorganismos contidos na biomassa, garantindo sua atividade e a biodegradação da matéria orgânica; e
- Concentração de sólidos dissolvidos, coloidais ou em suspensão que são encontrados no reator.

\subsubsection{MBR para o reuso da água}

A ausência de legislação ou norma especifica sobre o reuso de água a partir de efluentes tratados tem ignorado os interesses enconômicos e sociais desta prática.

Levando em consideração que parte dos processos que fazem reuso de água, essencialmente em centros urbanos, utilizam águas não potáveis, os efluentes de MBR (permeado) poderiam ser utilizados para reuso, já que atingem os padrões estabelecidos pelas legislações.

Os efluentes gerados por microfiltração ou ultrafiltração são livres de partículas, coliformes e vírus, mas não se retiram os nutrientes orgânicos e inorgânicos. O permeado é ocupado por bactérias heterotróficas, cuja população é controlada por sanificação complementar com cloro ou luz ultravioleta. O aparecimento de contaminantes orgânicos e inorgânicos nos efluentes limita o reuso desse tipo água para fins industriais ou comerciais que não suportam contaminantes químicos. A água de reuso que é estabelecida pela microfiltração e ultrafiltração tem uma qualidade que pode ser melhorada usando floculantes antes da fase de filtração (Schimmoller et al.,2001 apud Schneider e Tsutuya, 2001).

No Brasil, a NBR 13.969/1997 e o manual de Conservação e Reúso de Água em Edificações - ANA/FIESP \& SindusCon/ SP (2005) estabelece padrões de qualidade para que o esgoto tratado de origem doméstico ou com qualidade similar possa ser reutilizado.

\section{METODOLOGIA}

Trata-se de um estudo de revisão bibliográfica sistemática, adequada para buscas de consenso sobre alguma temática específica. Foi realizada uma busca em base de dados bibliográficas, como o Google Acadêmico, a fim de identificar artigos, teses e livros a respeito do assunto abordado. Os descritores utilizados para as pesquisas foram: tecnologia no sistema de tratamento de efluentes, biorreatores a membranas, e funcionamento de sistemas de tratamento de efluentes.

\section{CONSIDERAÇÕES FINAIS}

Como já mencionado neste artigo, por se tratar de uma tecnologia moderna, foram realizados poucos estudos no Brasil sobre os MBR. Porém, considerando o seu potencial elevado para a prática de reuso, sugere-se o desenvolvimen- 
to de novas pesquisas que possam avaliar os custos de instalações e operações.

O MBR apresenta-se como uma nova tecnologia imutável no setor industrial; contudo, restam dúvidas referentes ao custo-benefício para seu uso em escala municipal.

A reutilização da água é principalmente para irrigar as áreas privadas e públicas; todavia, sua produção é ligada a quatro estações de tratamento de esgoto doméstico e industrial que operam a partir de lodos ativados, filtração com areia, pedra e carvão, além da sua cloração. As instalações são semelhantes ao abastecimento de água potável, mas sua sinalização deve ser adequada para que não contenha a ingestão da água de reuso.

Apoiando-se nas premissas do direito ambiental, como origem da precaução, a aplicação dos MBR gerou mais aceitação, uma vez que apresenta melhor garantia na geração de água de reuso confiável e de qualidade.

Deste modo, a escassez local de água e a legislação restrita para descargas de efluentes devem estimular o reuso de esgoto tratado e lançar os MBR no setor municipal. Comparado aos processos tradicionais de tratamento de esgoto, que tem como necessidade mais etapas ou adaptações que os levam a obtenção de um produto apto ao reuso, sucedeu que para este tipo de tecnologia (MBR) apenas a cloração é suficiente.

Entende-se que o propósito deste artigo foi atingido, demonstrando a viabilidade de um efluente melhorado e com viáveis opções de reuso.

\section{REFERÊNCIAS}

Associação Brasileira de Normas Técnicas. 1987. Critérios para lançamento de efluentes líquidos industriais no sistema coletor público de esgoto sanitário - Procedimento: NBR 9800. Rio de Janeiro: ABNT.

Associação Brasileira de Normas Técnicas. 1997. Tanques sépticos - unidades de tratamento complementar e disposição final dos efluentes líquidos: projeto, construção e operação: NBR 13.969. Rio de Janeiro: ABNT.

Goulart, M.D.C.; Castilho, M. 2003. Bioindicadores de qualidade de água como ferramenta em estudos de impacto ambiental. Revista da FAPAM, ano 2, 153-164.

Maestri, R.S. 2007. Biorreator à membrana como alternativa para o tratamento de esgotos sanitários e reuso da água. Dissertação de Mestrado, Universidade Federal de Santa Catarina.

Schneider, R.P.; Tsutiya, M.T. 2001. Membranas Filtrantes para o tratamento de água, esgoto e água de reúso. São Paulo: ABES.

Silva, M.K. 2009. Biorreatores com Membranas: uma alternativa para o tratamento de efluentes. Tese de Doutorado, Universidade Federal do Rio Grande do Sul.

Viero, A.F. 2006. Avaliação do desempenho de um Biorreator com Membrana submersa para tratamento de efluente. Tese de Doutorado. Instituto Alberto Luiz Coimbra de Pós-Graduação e Pesquisa de Engenharia, Universidade Federal do Rio de Janeiro.

Von Sperling, M. 1997. Princípios do Tratamento Biológico de Águas Residuárias: Lodos Ativados. Vol. 4. Belo Horizonte: Universidade Federal de Minas Gerais.

Recebido: 21 maio 2019

Aprovado: 03 mar. 2020

DOI: $10.20985 / 1980-5160.2020 . v 15 n 1.1538$

Como citar: Batista, J.A., Costa, L.R., Oliveira, M.L. (2020), Biorreator à membrana-nova: tecnologia para tratamento de efluentes, Revista S\&G 15, No. 1, 11-17. https://revistasg.emnuvens.com.br/sg/article/view/1538 